\section{CardioRenal Medicine}

\title{
Vasodilation and Exercise Capacity in Patients with End-Stage Renal Disease: A Prospective Proof-of-Concept Study
}

\author{
Dirk Habedank $^{a} \quad$ Joerg C. Schefold ${ }^{b, f} \quad$ Carolin Bernhardt ${ }^{c}$ \\ Tim Karhausen $^{c}$ Wolfram Doehner ${ }^{c, d}$ Stefan D. Anker ${ }^{c, e}$ Petra Reinke ${ }^{b}$ \\ ${ }^{a}$ Medizinische Klinik Kardiologie, DRK-Kliniken Berlin-Köpenick, and Departments of \\ ${ }^{b}$ Nephrology and Intensive Care Medicine and ${ }^{C}$ Cardiology, Applied Cachexia Research, and \\ dStroke Research Centre, Charité Campus Virchow-Klinikum, Berlin, and e Department of \\ Cardiology and Pneumology, Innovative Clinical Trials, University of Göttingen, Göttingen, \\ Germany; ${ }^{f}$ Department of Intensive Care Medicine, Inselspital, Bern University Hospital, \\ Bern, Switzerland
}

\section{Key Words}

Vasodilation $\cdot$ Exercise $\cdot$ Chronic kidney disease $\cdot$ Chronic heart failure $\cdot$ Inflammation $\cdot$ Sepsis

\begin{abstract}
Background: Previous data have pointed to the fact that vascular function is significantly impaired in patients with end-stage renal disease (ESRD). We aimed to better characterise vasodilation and exercise capacity in both ESRD and chronic heart failure (CHF) patients. Methods: A total of 30 ESRD patients ( 23 male; mean age $45.7 \pm 9.9$ years) were included in a prospective proof-of-concept study at a tertiary care academic centre. The patients underwent forearm venous plethysmography with post-ischaemic peak blood flow (PF) and flow-dependent flow (FDF) testing as well as cardiopulmonary exercise testing during the morning of the day following the last haemodialysis. After matching for age, gender, and body mass index, the data were compared to 30 patients with $\mathrm{CHF}$ and 20 age-matched healthy controls. Results: PF in ESRD patients was reduced when compared to that in CHF patients ( $12.5 \pm 4.2$ vs. 15.6 $\pm 6.9 \mathrm{ml} / 100 \mathrm{ml} / \mathrm{min} ; \mathrm{p}=0.048)$ and healthy controls $(26.4 \pm 9.3 \mathrm{ml} / 100 \mathrm{ml} / \mathrm{min} ; \mathrm{p}<0.001)$. When compared to controls, FDF was significantly reduced in ESRD patients (7.6 \pm 3.1 vs. 6.0 $\pm 2.5 \mathrm{ml} / 100 \mathrm{ml} / \mathrm{min} ; \mathrm{p}=0.03$ ), but not in CHF patients, whereas resting blood flow did not differ between the ESRD, CHF, and healthy control groups. In contrast to indices of vasodilative capacity, maximum exercise capacity $\left(\right.$ peakVO ${ }_{2}$ ) was higher in ESRD when compared to CHF patients ( $23.8 \pm 7.3$ vs. $18.8 \pm 5.2 \mathrm{ml} / \mathrm{min} / \mathrm{kg})$, but significantly impaired when compared to controls (32.8 $\pm 6.7 \mathrm{ml} / \mathrm{min} / \mathrm{kg} ; \mathrm{p}<0.001)$. Conclusion: In this proof-of-concept study, ex-
\end{abstract}


Habedank et al.: Vasodilation and Exercise Capacity in Patients with End-Stage Renal Disease: A Prospective Proof-of-Concept Study

ercise capacity was relatively preserved, while vasodilative capacity was substantially impaired in ESRD patients. Additional studies are warranted to examine the underlying mechanisms and potential clinical implications of our findings.

(c) 2016 S. Karger AG, Basel

\section{Introduction}

Renal failure requiring initiation of renal replacement therapy affects all organ systems and is associated with high mortality rates in both the chronic [1-3] and the acute clinical setting [4-6]. The excessive morbidity and mortality of patients with end-stage renal disease (ESRD) seems mostly due to cardiovascular complications [1-3, 7-9]. Therefore, it seems perfectly acceptable that ESRD both on and off renal replacement therapy may be regarded a vasculopathic state in itself [10]. Several cofactors (e.g. diabetes, age, and time on dialysis) may be regarded key determinants of the overall (cardio-)vascular risk $[1,2,9,11]$. In addition, cofactors such as malnutrition/cachexia $[2,12,13]$ and induction of multiple inflammatory pathways [14-18] contribute to increased vasculopathy and, finally, adverse outcomes in affected patients.

Macroangiopathy represents the (often clinically visible) endpoint of vasculopathy, whereas the initial stage includes more subtle dysfunctions of the vascular endothelium which may require more sophisticated imaging and/or functional testing [1, 10, 19-21]. Theoretically, however, early detection of endothelial dysfunction may help to improve patients' prognosis via better risk stratification of the respective cohorts and/or timely induction of targeted therapy. However, it should be noted that renal failure and cardiac failure interact on endothelium-derived vasodilative capacity. Previous data have demonstrated that in patients with chronic heart failure (CHF), peripheral endothelial dysfunction occurs at early clinical stages but predicts long-term adverse outcome [20]. On CKD patients, however, the data are scarcer. Following correction for traditional cardiovascular risk factors, the data indicate that especially patients close to initiation of dialysis or ESRD patients on dialysis in particular seem to have significant endothelial dysfunction [1, 10, 19, 21, 22]. Nevertheless, a diminished vasodilative capacity may also be observed at earlier stages, i.e. at Kidney Disease Outcomes Quality Initiative (KDOQI) stages 2 and 3.

In an effort to better characterise vasodilative capacity and exercise capacity in ESRD, we investigated forearm post-ischaemic (peak) blood flow (PF; in an effort to define the maximum possible vasodilation), flow-dependent flow (FDF) (both assessed by non-invasive measures), and peak oxygen uptake per body weight $\left(\mathrm{peakVO}_{2}\right)$. For assessment of endothelial function, forearm venous plethysmography was chosen, which may be regarded as an established noninvasive method with a long-standing record. Transient ischaemia provokes the release of nitric oxide (NO), resulting in vasodilation which can be quantified as an index of vasomotor function and measured by means of ultrasound or strain gauge. It allows a differentiation between maximum possible flow (i.e. PF) resulting from ischaemia and NO-mediated, i.e. flow-dependent, flow (FDF) resulting from endothelium-derived NO release derived from shear stress. However, the assessment of endothelial function requires comparable and comprehensive rating of the cardiovascular system, which can be characterised by exercise capacity with maximum oxygen uptake (as in peakVO $\mathrm{K}_{2}$ ) as a 'gold standard' for CHF and also as a strong predictor of survival in ESRD [23-26].

In the current proof-of-concept investigation, we set out to investigate whether endothelial function in ESRD is proportional to exercise capacity, and we compared this relation to patients with CHF and healthy control subjects. Moreover, we were interested in whether age and time since initiation of chronic dialysis would be factors influencing endothelial function. 


\section{CardioRenal Medicine}

\begin{tabular}{l|l}
\hline Cardiorenal Med 2017;7:50-59 \\
\hline DOI: 10.1159/000449174 & $\begin{array}{l}\text { ( ) 2016 S. Karger AG, Basel } \\
\text { www.karger.com/crm }\end{array}$ \\
\hline
\end{tabular}

Habedank et al.: Vasodilation and Exercise Capacity in Patients with End-Stage Renal Disease: A Prospective Proof-of-Concept Study

\section{Subjects and Methods}

\section{Study Cohorts and Study Visits}

A total of 30 ESRD patients (23 male; mean age $45.7 \pm 9.9$ years, range $26-64 ; 87 \%$ on haemodialysis) were included in a single-centre prospective observational proof-of-concept study at the outpatient clinic of a tertiary care academic centre (Kidney Transplantation Centre, Charité - Universitätsmedizin Berlin, Berlin, Germany). All patients were awaiting kidney transplantation, either on the Eurotransplant waiting list ( $\mathrm{n}=$ 15) or scheduled for kidney transplantation from living donors (i.e. from relatives; $n=15$ ). The median time since initiation of chronic haemodialysis was 18.0 months (range 1-240). With regard to examination of the participating subjects, special attention was paid to the interval between the last haemodialysis and the respective study visit, due to the fact that most of the parameters could theoretically be influenced by fluid overflow, imbalance of electrolytes, or accumulation of metabolites. Thus, an interval of approximately 19-22 $\mathrm{h}$ (the typical time interval between the end of morning dialysis and the study visit the following morning) was chosen. In an effort to minimise any potential bias introduced by fluid overload, a difference from post-dialysis weight ('dry weight') of less than $1 \%$ (or $1 \mathrm{~kg}$ ) was allowed for. Patients on peritoneal dialysis were excluded from the analysis. All patients had been fasting before venous plethysmography and drawing of blood samples, whereas the exercise test was performed after a light breakfast and a short resting period. Medication was taken with the breakfast but not before plethysmography.

In all, 30 CHF patients were recruited from the CHF outpatient clinic of the Charité - Universitätsmedizin Berlin, and they were matched for age, gender, and body mass index. The aetiologies of heart failure were dilative cardiomyopathy $(n=16)$ and coronary heart disease $(n=14 ; 47 \%)$. Twenty healthy volunteers of the same age served as controls.

The study was approved by the local ethics committee (Ethikkommission Charité, Berlin, No. 16003) and informed written consent was obtained from all patients. The study was performed in accordance with the ethical guidelines established in the Declaration of Helsinki.

\section{Assessment of Vascular Capacity and Peripheral Blood Flow}

In general, plethysmography may allow checking for volume changes in the area of interest, since such changes were shown to be directly related to the amount of blood flow. In an effort to assess peripheral blood flow and vascular capacity, we applied venous occlusion plethysmography using a commercial EC6 plethysmography device (Hokanson Inc., Bellevue, Wash., USA). As is proposed for performing these measurements, the subjects were requested to rest in the supine position for at least $15 \mathrm{~min}$, and forearm blood flow was determined using a mercury-in-silastic strain gauge (Hokanson Inc.). A circumferential cuff around the right upper arm was connected to a rapid inflation pump with an air source and solenoid valves, used to inflate and deflate the occlusion cuff rapidly to the required pressure of $40 \mathrm{~mm} \mathrm{Hg}$. After the resting period, the blood flow was measured on the arm without the dialysis fistula and calculated as resting flow. To measure the PF, the cuff was inflated to suprasystolic pressures (i.e. $30 \mathrm{~mm} \mathrm{Hg}$ above the systolic blood pressure) for $3 \mathrm{~min}$. Blood flow was measured after release of the cuff in 10 -second intervals for at least $2 \mathrm{~min}$. The highest flow results were considered to represent PF.

For assessment of FDF, which may serve as an estimate of endothelium-dependent vasodilator capacity, a second sphygmomanometer cuff was placed distal to the strain gauge on the forearm and inflated to suprasystolic levels for $2 \mathrm{~min}$. After sudden deflation of this cuff, the increase in shear stress due to the increased flow through the brachial artery causes endothelium-derived NO release. Following this re-induction of increased brachial artery blood flow, consecutive blood flow was then measured every $10 \mathrm{~s}$ for a total period of $90 \mathrm{~s}$. Absolute values derived from the plethysmographic measurements are given as millilitres per 100 $\mathrm{ml}$ tissue per minute $(\mathrm{ml} / 100 \mathrm{ml} / \mathrm{min})$.

\section{Exercise Testing}

A symptom-limited cardiopulmonary exercise test was performed on a treadmill according to the modified Naughton protocol. Expired gas was sampled through a 'Rudolph mask' conveyed to a spirometer and to oxygen/carbon dioxide detectors (Medgraphics, Vadnais Heights, Minn., USA). $\mathrm{VO}_{2}$ and $\mathrm{VCO}_{2}$, the endtidal expiratory gas concentrations $\mathrm{p}_{\mathrm{ET}} \mathrm{O}_{2}$ and $\mathrm{p}_{\mathrm{ET}} \mathrm{CO}_{2}$, and ventilation per minute VE were measured breath by breath, and the average of 5 out of 7 breaths was calculated automatically. All patients were monitored with a continuous 12-lead electrocardiogram (CardioPerfect; Welch Allyn, New York, N.Y., USA), and non-invasive blood pressure measurement was conducted at rest, at every stage of the exercise, and during recovery. Data at rest and $\mathrm{FEV}_{1}$ (forced expiratory volume in the first second) were determined after 3 min of quiet standing 


\section{CardioRenal Medicine}

\begin{tabular}{l|l}
\hline \multicolumn{2}{l}{ Cardiorenal Med 2017;7:50-59 } \\
\hline DOI: 10.1159/000449174 & $\begin{array}{l}\text { @ 2016 S. Karger AG, Basel } \\
\text { www.karger.com/crm }\end{array}$ \\
\hline
\end{tabular}

Habedank et al.: Vasodilation and Exercise Capacity in Patients with End-Stage Renal Disease: A Prospective Proof-of-Concept Study

and breathing via the mask. Exercise time was recorded and symptoms at peak exercise were documented. All patients exercised until limited by symptoms. For peakVO 2 , peakVCO of each parameter in the final $30 \mathrm{~s}$ of exercise were used. Respiratory exchange ratio was used as a marker of exhaustion and calculated from peakVCO $\mathrm{C}_{2}$ and peakVO $\mathrm{K}_{2}$ (i.e. peakVCO $\mathrm{C}_{2} / \mathrm{peakVO}_{2}$ ). Ventilatory efficiency during exercise testing was measured by plotting $\mathrm{VE}$ against $\mathrm{VCO}_{2}$, values due to hyperventilation (acidosis) in the last minutes of exercise were excluded, and the slope of the revealed linear relationship $\left(\mathrm{VE} / \mathrm{VCO}_{2}\right.$ slope) was calculated by linear regression and accepted if the correlation coefficient $r$ was $>0.95$.

Blood Samples

Peripheral venous blood samples for the measurement of creatinine, electrolytes, and haemoglobin were taken at the beginning of the visit after $30 \mathrm{~min}$ of rest in a fasting condition and analysed immediately in a certified laboratory (Charité - Universitätsmedizin).

\section{Statistical Analysis}

All analyses were performed using SPSS 18.0 (IBM, Chicago, Ill., USA). Data are given as means \pm SD for parametric variables, and as medians with interquartile ranges for the non-parametric variables 'time since (initiation of first dialysis' and New York Heart Association (NYHA) stage. Differences between the three groups (ESRD, CHF, and controls) were calculated using two-tailed Student's unpaired $t$ test and the MannWhitney test, as appropriate. The distribution of gender (i.e. proportion of females) and comorbidities (including diabetes, hypertension, and medication) was compared by $\chi^{2}$ testing. Correlations between different quantitative parameters were assessed by linear or by Spearman's correlation, as appropriate. $\mathrm{p}<$ 0.05 was considered significant.

\section{Results}

\section{Patient Characteristics}

The characteristics of the study population, including (co-)medications, are outlined in table 1 . The prevalence of arterial hypertension in about $90 \%$ of the subjects marks a relevant comorbidity but seems rather unavoidable in ESRD populations. The majority of the patients trended for normalization of blood pressure under therapy, with mean pressures at rest of $126.2 \pm 19.9 / 75.0 \pm 10.5 \mathrm{~mm} \mathrm{Hg}$ (systolic/diastolic). At exercise, the respective mean systolic and diastolic blood pressures were $161.5 \pm 28.8$ and $79.1 \pm 8.9 \mathrm{~mm} \mathrm{Hg}$. Diverse aetiologies of renal failure were noted in the study group, which may be due to the fact that patients from a tertiary care academic referral centre were included. Exercise insufficiency was not prevalent in the ESRD cohort, and thus, by definition, the majority of the patients were clinically in NYHA stage I, subjectively corresponding to only slightly impaired everyday capacity and an average peakVO $\mathrm{N}_{2}$ of about $22 \mathrm{ml} / \mathrm{min} / \mathrm{kg}$. An additional analysis was performed to characterise residual renal function and the haemodialysis dose applied, because both factors may influence endothelial function and exercise capacity. Although measured on the off-dialysis day, the mean creatinine levels were relatively high (i.e. $7.4 \pm 2.6 \mathrm{mg} / \mathrm{dl}$ ). However, due to insufficient data provided by ambulatory care practitioners, a formal calculation of dialysis dose (i.e. by Kt/V) was not possible. Therefore, we used creatinine levels as a rough approximation to short-time dialysis quality.

The comparator cohorts with CHF patients and healthy subjects were matched for age and gender, but they differed expectedly for concomitant medication and blood pressure (table 2). All study participants underwent exercise testing until limited by symptoms, and exhaustion was defined as a respiratory ratio $\left(\mathrm{VCO}_{2} / \mathrm{VO}_{2}\right)$ of $1.1 \pm 0.1$.

\section{Vasodilative Capacity}

No difference in blood flow at rest between ESRD patients $(4.8 \pm 2.5 \mathrm{ml} / 100 \mathrm{ml} / \mathrm{min})$, CHF patients $(4.7 \pm 3.6 \mathrm{ml} / 100 \mathrm{ml} / \mathrm{min})$, and healthy subjects $(5.0 \pm 2.3 \mathrm{ml} / 100 \mathrm{ml} / \mathrm{min})$ (all 
Habedank et al.: Vasodilation and Exercise Capacity in Patients with End-Stage Rena Disease: A Prospective Proof-of-Concept Study

Table 1. Baseline characteristics of the ESRD patients $(n=30)$

Demographics

Age, years

Male

Time since initiation of haemodialysis, months

Body mass index

Aetiology of renal failure

Glomerulonephritis

Diabetic nephropathy

Polycystic kidney disease

Intrarenal cause/toxicity

Post-pyelonephritis

Others ${ }^{\mathrm{a}}$

Unknown

Concomitant diseases

Arterial hypertension

Coronary heart disease

Diabetes mellitus

Chronic viral infection (hepatitis B/C, HIV)

Clinical data

NYHA stage

Blood pressure at rest, $\mathrm{mm} \mathrm{Hg}$

Heart rate at rest, beats/min

\section{Medication}

Beta-blocker

Angiotensin-converting enzyme inhibitor/angiotensin receptor blocker

Diuretics

Ca antagonist

Number of antihypertensive drugs

Acetylsalicylate

Statins

Laboratory values

Serum creatinine, $\mathrm{mg} / \mathrm{dl}$

Serum urea, $\mathrm{mg} / \mathrm{dl}$

Serum uric acid, $\mathrm{mg} / \mathrm{dl}$

Haemoglobin, mg/dl

$\mathrm{HbA}_{1 \mathrm{c}}, \%$

Total cholesterol, mg/dl
$45.7 \pm 9.9$

23 (76.7)

$18.0[12.5]$

$24.5 \pm 4.0$

$3(10)$

$3(10)$

$3(10)$

2 (6.7)

$2(6.7)$

$6(20)$

$11(40)$

$26(86.7)$

$19(25.0)$

18 (23.7)

$6(7.9)$

0.8 [1-3]

$124.5 \pm 17.8$

$81.7 \pm 15.7$

$10(33.3)$

11 (36.7)

25 (83.3)

$5(36.8)$

2.0 [0-7]

1 (3.3)

$6(20)$

Values are presented as $\mathrm{n}(\%)$, mean $\pm \mathrm{SD}$, or median [interquartile range]. ${ }^{\text {a }}$ Indicates the following diagnoses: Alport syndrome, IgA nephropathy, Fabry disease, granulomatosis with polyangiitis (Wegener's), or renal hypoplasia/nephrosclerosis.

$\mathrm{p}>0.6$ ) was noted. Maximum vasodilation (peak flow) after ischaemic provocation in ESRD patients $(12.5 \pm 4.2 \mathrm{ml} / 100 \mathrm{ml} / \mathrm{min})$ was lower than in CHF patients $(15.6 \pm 6.9 \mathrm{ml} / 100 \mathrm{ml} /$ $\min ; \mathrm{p}=0.048 \mathrm{vs}$. ESRD $)$ and substantially lower than in healthy controls $(26.4 \pm 9.3 \mathrm{ml} / 100$ $\mathrm{ml} / \mathrm{min}$; $\mathrm{p}<0.001$ vs. ESRD). FDF was diminished in both ESRD patients $(6.0 \pm 2.5 \mathrm{ml} / 100$ $\mathrm{ml} / \mathrm{min})$ and CHF patients $(7.4 \pm 4.6 \mathrm{ml} / 100 \mathrm{ml} / \mathrm{min} ; \mathrm{p}=0.14)$ when compared to healthy subjects $(7.6 \pm 3.1 \mathrm{ml} / 100 \mathrm{ml} / \mathrm{min} ; \mathrm{p}=0.03 \mathrm{vs}$. ESRD $)$. Between-group comparisons are given in figure 1.

Several parameters were assessed as cofactors for flow at rest, PF, and FDF. A correlation with age was not found in ESRD patients. In this group, the correlation coefficient $r$ between 
Table 2. Between-group comparison of baseline demographics and disease severity

\begin{tabular}{|c|c|c|c|c|}
\hline & $\begin{array}{l}\text { ESRD } \\
\text { patients } \\
(n=30)\end{array}$ & $\begin{array}{l}\text { CHF } \\
\text { patients } \\
(n=30)\end{array}$ & $\begin{array}{l}\text { Healthy } \\
\text { controls } \\
(n=20)\end{array}$ & $\begin{array}{l}\text { Between-group } \\
\text { p value }\end{array}$ \\
\hline Age, years & $45.7 \pm 9.9$ & $48.9 \pm 7.6$ & $49.3 \pm 7.4$ & n.s. \\
\hline Female & $7(23.3)$ & $6(20)$ & $5(20)$ & n.s. ${ }^{\mathrm{a}}$ \\
\hline Body mass index & $24.5 \pm 4.0$ & $27.2 \pm 4.4$ & $25.7 \pm 4.4$ & n.s. \\
\hline Coronary heart disease & $4(13.3)$ & $14(47)$ & - & $0.001^{\mathrm{a}}$ \\
\hline Diabetes mellitus & $6(20)$ & $8(26.7)$ & - & n.s. ${ }^{\mathrm{a}}$ \\
\hline NYHA stage & $0.9[1-3]$ & $3.0[1-4]$ & - & $<0.001^{\mathrm{b}}$ \\
\hline Systolic blood pressure at rest, $\mathrm{mm} \mathrm{Hg}$ & $126.2 \pm 19.9$ & $114.2 \pm 16.3$ & $124.9 \pm 11.8$ & $<0.01$ \\
\hline Diastolic blood pressure at rest, $\mathrm{mm} \mathrm{Hg}$ & $75.7 \pm 11.7$ & $71.8 \pm 17.5$ & $73.7 \pm 15.0$ & n.s. \\
\hline Serum creatinine, $\mathrm{mg} / \mathrm{dl}$ & $7.4 \pm 2.6$ & $1.3 \pm 0.9$ & - & $<0.001$ \\
\hline
\end{tabular}

Values are presented as $\mathrm{n}(\%)$, mean $\pm \mathrm{SD}$, or median [interquartile range]. n.s. $=$ Not significant. ${ }^{\mathrm{a}} \chi^{2}$ test. $^{\mathrm{b}}$ MannWhitney U test.

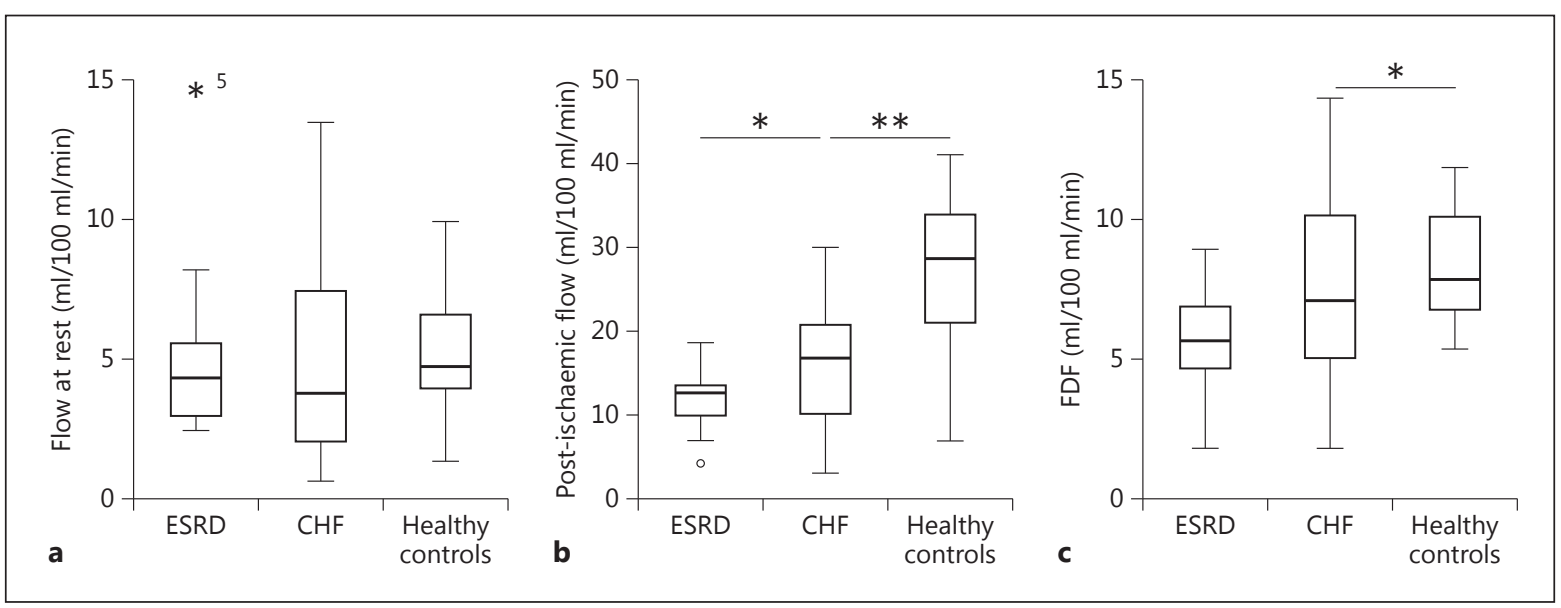

Fig. 1. Blood flow at rest (a), post-ischaemic flow (b), and FDF (c) in patients with ESRD and CHF and in healthy controls (means and percentiles are given). ${ }^{*} \mathrm{p}<0.05,{ }^{* *} \mathrm{p}<0.001$.

age and flow at rest was -0.3 , between age and PF it was 0.11 , and between age and FDF it was -0.19 (all $p>0.1$ ). Regarding gender as a cofactor, there was a non-significant tendency towards lower flow in female patients. The flow at rest in males versus females was $4.9 \pm 2.6$ versus $4.5 \pm 2.1 \mathrm{ml} / 100 \mathrm{ml} / \mathrm{min}$, $\mathrm{PF}$ was $13.2 \pm 4.2$ versus $10.4 \pm 3.7 \mathrm{ml} / 100 \mathrm{ml} / \mathrm{min}$, and FDF was $6.2 \pm 2.3$ versus $5.5 \pm 3.2 \mathrm{ml} / 100 \mathrm{ml} / \mathrm{min}$ ( $\mathrm{p}>0.1$ for all comparisons). Additionally, neither time since initiation of (first) dialysis nor current creatinine level nor peakVO $\mathrm{F}_{2}$ was found to correlate with FR, PF, or FDF. In addition, no respective correlation was found in either the CHF or the healthy control group. In addition, no gender-dependent differences regarding flow variables were noted in the CHF and healthy control groups $(p>0.08)$.

\section{Exercise Capacity and Ventilatory Efficiency}

Maximum exercise capacity (i.e. peakVO $\left.\mathrm{K}_{2}\right)$ was impaired in ESRD patients $(23.8 \pm 7.3 \mathrm{ml} /$ $\mathrm{min} / \mathrm{kg}$ ), corresponding to an anaerobic threshold at $13.6 \pm 3.8 \mathrm{ml} / \mathrm{min} / \mathrm{kg}$ and a ventilatory 
Fig. 2. peakVO $\mathrm{K}_{2}$ in $\mathrm{ESRD}$ and $\mathrm{CHF}$ patients and in healthy controls (means and percentiles are given). ${ }^{*} \mathrm{p}<0.01$.

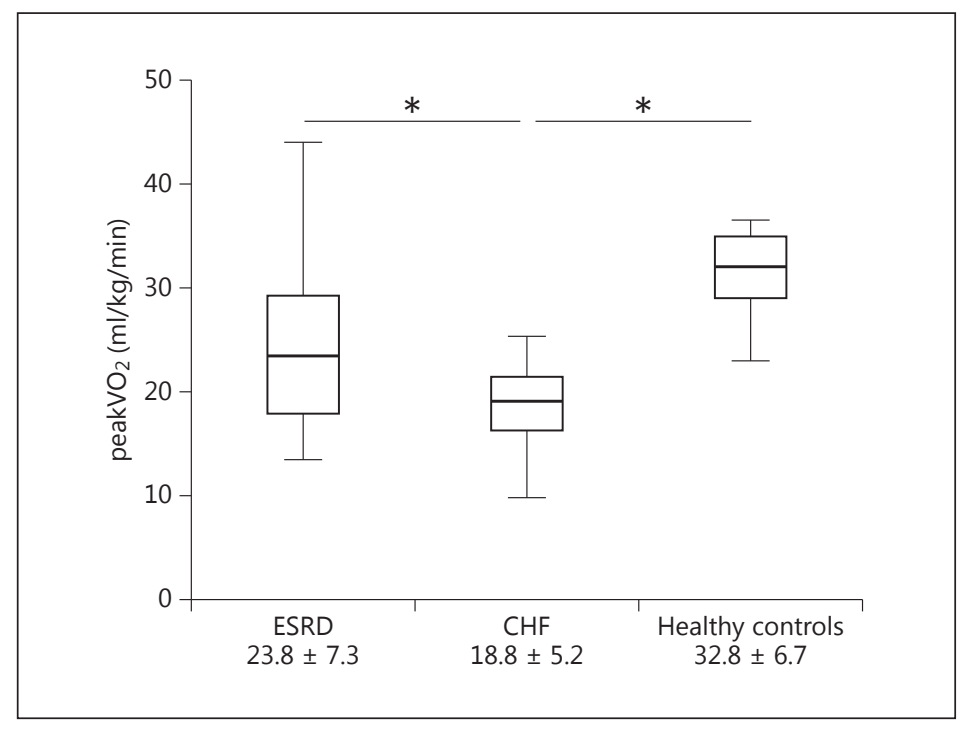

efficiency ( $\mathrm{VE} / \mathrm{VCO}_{2}$ slope) of $29.3 \pm 5.6$. Inverse correlations of age with peakVO $\mathrm{O}_{2}(\mathrm{r}=-0.42$; $\mathrm{p}<0.001)$ and $\mathrm{VE} / \mathrm{VCO}_{2}$ slope were noted $(\mathrm{r}=0.38 ; \mathrm{p}<0.001)$. peakVO $\mathrm{VO}_{2}$ correlated inversely with time since initiation of dialysis $(\rho=-0.26 ; p=0.027)$ but not with serum creatinine levels $(\mathrm{r}=0.24 ; \mathrm{p}=0.08)$. Similarly to peakVO $\mathrm{V}_{2}$, ventilatory efficiency $\left(\mathrm{VE} / \mathrm{VCO}_{2}\right.$ slope $)$ correlated with age $(r=0.38 ; p=0.001)$ and haemoglobin concentrations $(r=-0.32 ; p=0.013)$.

The peakVO ${ }_{2}$ of the CHF patients was significantly lower $(18.8 \pm 5.2 \mathrm{ml} / \mathrm{min} / \mathrm{kg})$ when compared to ESRD patients $(\mathrm{p}=0.003)$ and healthy subjects $(32.8 \pm 6.7 \mathrm{ml} / \mathrm{min} / \mathrm{kg} ; \mathrm{p}<$ $0.001)$. Correspondingly, the $\mathrm{VE} / \mathrm{VCO}_{2}$ slope was highest in $\mathrm{CHF}$ patients $(34.1 \pm 7.2)$, with healthy controls at $28.7 \pm 5.2(\mathrm{p}=0.007)$. For comparison of peakVO $\mathrm{O}_{2}$ levels, please see figure 2 .

\section{Discussion}

Here we demonstrated that in ESRD, endothelium-derived vasodilative capacity is reduced to an extent typically observed in NYHA stage III heart failure patients despite better exercise capacity. ESRD patients were found to have a significantly lower FDF than agematched healthy controls, and the PF was impaired by 48\% (again corresponding to levels of patients with advanced heart failure). However, we noted no correlations of indices of endothelial function with cofactors such as age, $\mathrm{peakVO}_{2}$, or time since initiation of dialysis.

The 'gold standard' (peakVO $\mathrm{K}_{2}$ ) of exercise testing was evaluated more than 25 years ago in ESRD patients [26] and was shown to predict survival in this population. In the current analysis, we observed rather high peakVO $\mathrm{N}_{2}$ levels (about $24 \mathrm{ml} / \mathrm{min} / \mathrm{kg}$ ) in our population that may be regarded as being in the higher range when compared to other investigations. Thus, the physical condition of the cohort investigated here may be rather preserved, and impaired FDF and PF may indicate that vascular function in older or more comorbid patients may even be worse. Nevertheless, a methodological comparison of FDF measurements in ESRD patients may be challenging due to the fact that the vast majority of studies used ultrasound to measure flow-dependent vasodilatation instead of venous occlusion plethysmography. However, the latter may be easier to perform, and normal levels from healthy volunteers are available [27]. The normal values provided by Boutcher and Boutcher [28] are 


\section{CardioRenal Medicine}

\begin{tabular}{l|l}
\hline Cardiorenal Med 2017;7:50-59 \\
\hline DOI: 10.1159/000449174 & $\begin{array}{l}\text { @ 2016 S. Karger AG, Basel } \\
\text { www.karger.com/crm }\end{array}$ \\
\hline
\end{tabular}

Habedank et al.: Vasodilation and Exercise Capacity in Patients with End-Stage Renal Disease: A Prospective Proof-of-Concept Study

higher (max. vasodilative capacity $35 \pm 10 \mathrm{ml} / 100 \mathrm{ml} / \mathrm{min}$ ) but derive from considerably younger male subjects. In addition, the normal value provided by Meredith et al. [29] for peak flow in younger healthy volunteers was $26.5 \pm 2.1 \mathrm{ml} / 100 \mathrm{ml} / \mathrm{min}$, but this group used a different methodological approach. In summary, studies on endothelial function in ESRD demonstrate impaired FDF in relation to normal subjects. However, as outlined above, these data are challenging to compare due to significant methodological differences.

A further limitation of all studies may consist in the fact that the basic assumption is that FDF is simply NO dependent. However, endothelial function seems much more complex, since e.g. adenosine, cyclooxygenase metabolites, and potassium channels may contribute to vascular relaxation [30]. Nevertheless, as these are at least partly reflected by peak flow measurements, we are convinced that the combination of both impaired FDF and impaired PF indicates severe endothelial dysfunction in ESRD patients. London et al. [31] aimed to avoid any such limitations and proposed a novel parameter, i.e. 'flow debt repayment', derived from strain gauge plethysmography, which may characterise endothelium-derived vasodilation. This parameter was shown to be predictive of all-cause mortality of ESRD patients. However, it should be noted that this parameter requires sophisticated assessment, is not broadly accepted, and lacks reference ranges.

Our study has further limitations that require discussion. First, it seems important to note that only a small sample from a single centre was investigated. Thus, a key limitation might primarily be driven by the study design, and inherent limitations including the proofof-concept character of the study must be borne in mind when interpreting our data. Moreover, we are currently unable to examine the underlying mechanisms and clinical implications of the effects observed. Additional studies are therefore warranted. Second, as mentioned before, due to the complexity of the biological function of the endothelium, endothelial function may not simply be reduced to being NO dependent. Consecutively, FDF must be interpreted as only partially reflecting the complexity of the endothelial response. Nevertheless, one of the strengths of this study might be that we aimed to employ rather elaborate methods for PF and FDF assessment.

In the present study we did not find that time since initiation of dialysis (i.e. total time on dialysis) correlates with indices of endothelial function, and this may be due to the fact that the onset of renal failure is not simply linked to starting of renal replacement therapy. Nevertheless, endothelial dysfunction was shown to be present in early stages of CKD [1, 2, 10, 19, $21,32]$, and data from renal transplant recipients demonstrate that this condition seems at least partly reversible [33].

In summary, in our proof-of-concept study involving a limited number of study patients, the endothelium-derived vasodilative capacity of ESRD patients was found to be significantly reduced by about $20 \%$ (FDF) and $48 \%$ (PF) when compared to normal subjects, which corresponds to levels observed in patients with advanced CHF (NYHA stage III). Impaired endothelial function in ESRD stands in contrast to rather preserved exercise capacities. We speculate from our data that the fairly preserved exercise capacity in the cohort under investigation may point to the fact that endothelial dysfunction precedes cardiopulmonary limitations by a substantial period in time. Additional studies thus seem warranted to examine the underlying mechanisms and potential clinical implications of our findings.

\section{Statement of Ethics}

This study was approved by the local ethics committee (Ethikkommission Charité, Berlin, Germany, No. 16003), and written informed consent was obtained from all patients. The study was performed in accordance with the Declaration of Helsinki. 


\section{CardioRenal Medicine}

\begin{tabular}{l|l}
\hline Cardiorenal Med 2017;7:50-59 \\
\hline DOI: 10.1159/000449174 & $\begin{array}{l}\text { ( 2)16 S. Karger AG, Basel } \\
\text { www.karger.com/crm }\end{array}$ \\
\hline
\end{tabular}

Habedank et al.: Vasodilation and Exercise Capacity in Patients with End-Stage Renal Disease: A Prospective Proof-of-Concept Study

\section{Disclosure Statement}

The authors declare that there is no conflict of interest.

\section{References}

1 Di Lullo L, House A, Gorini A, Santoboni A, Russo D, Ronco C: Chronic kidney disease and cardiovascular complications. Heart Fail Rev 2015;20:259-272.

2 Tonelli M, Wiebe N, Culleton B, House A, Rabbat C, Fok M, McAlister F, Garg AX: Chronic kidney disease and mortality risk: a systematic review. J Am Soc Nephrol 2006;17:2034-2047.

3 Go AS, Chertow GM, Fan D, McCulloch CE, Hsu CY: Chronic kidney disease and the risks of death, cardiovascular events, and hospitalization. N Engl J Med 2004;351:1296-1305.

4 Basile DP, Anderson MD, Sutton TA: Pathophysiology of acute kidney injury. Compr Physiol 2012;2:13031353.

5 Vinsonneau C, Camus C, Combes A, Costa de Beauregard MA, Klouche K, Boulain T, Pallot JL, Chiche JD, Taupin $\mathrm{P}$, Landais $\mathrm{P}$, et al: Continuous venovenous haemodiafiltration versus intermittent haemodialysis for acute renal failure in patients with multiple-organ dysfunction syndrome: a multicentre randomised trial. Lancet 2006;368:379-385.

6 Schefold JC, von Haehling S, Pschowski R, Bender T, Berkmann C, Briegel S, Hasper D, Jörres A: The effect of continuous versus intermittent renal replacement therapy on the outcome of critically ill patients with acute renal failure (CONVINT): a prospective randomized controlled trial. Critical Care 2014;18:R11.

7 Herzog CA, Ma JZ, Collins AJ: Poor long-term survival after acute myocardial infarction among patients on longterm dialysis. N Engl J Med 1998;339:799-805.

8 Wright RS, Reeder GS, Herzog CA, Albright RC, Williams BA, Dvorak DL, Miller WL, Murphy JG, Kopecky SL, Jaffe AS: Acute myocardial infarction and renal dysfunction: a high-risk combination. Ann Intern Med 2002; 137:563-570.

9 Zachariah D, Kalra PR, Roberts PR: Sudden cardiac death in end stage renal disease: unlocking the mystery. J Nephrol 2015;28:133-141.

10 Luke RG: Chronic renal failure - a vasculopathic state. N Engl J Med 1998;339:841-843.

11 Kiuchi MG, Mion D Jr: Chronic kidney disease and risk factors responsible for sudden cardiac death: a whiff of hope? Kidney Res Clin Pract 2016;35:3-9.

12 Ikizler TA, Cano NJ, Franch H, Fouque D, Himmelfarb J, Kalantar-Zadeh K, Kuhlmann MK, Stenvinkel P, TerWee P, Teta D, et al: Prevention and treatment of protein energy wasting in chronic kidney disease patients: a consensus statement by the International Society of Renal Nutrition and Metabolism. Kidney Int 2013;84: 1096-1107.

13 Fernández-Reyes MJ, Alvarez-Ude F, Sánchez R, Mon C, Iglesias P, Díez JJ, Vázquez A: Inflammation and malnutrition as predictors of mortality in patients on hemodialysis. J Nephrol 2002;15:136-143.

14 Kaysen GA: Progressive inflammation and wasting in patients with ESRD. Clin J Am Soc Nephrol 2014;9:225226.

15 Kaysen GA, KumarV: Inflammation in ESRD: causes and potential consequences. J Ren Nutr 2003;13:158-160

16 Raj DS, Shah H, Shah VO, Ferrando A, Bankhurst A, Wolfe R, Zager PG: Markers of inflammation, proteolysis, and apoptosis in ESRD. Am J Kidney Dis 2003;42:1212-1220.

17 Tripepi G, Mallamaci F, Zoccali C: Inflammation markers, adhesion molecules, and all-cause and cardiovascular mortality in patients with ESRD: searching for the best risk marker by multivariate modeling. J Am Soc Nephrol 2005;16(suppl 1):S83-S88.

18 Schefold JC, Zeden JP, Fotopoulou C, von Haehling S, Pschowski R, Hasper D, Volk HD, Schuett C, Reinke P: Increased indoleamine 2,3-dioxygenase (IDO) activity and elevated serum levels of tryptophan catabolites in patients with chronic kidney disease: a possible link between chronic inflammation and uraemic symptoms. Nephrol Dial Transplant 2009;24:1901-1908.

19 Annuk M, Lind L, Linde T, Fellström B: Impaired endothelium-dependent vasodilatation in renal failure in humans. Nephrol Dial Transplant 2001;16:302-306.

20 Heitzer T, Baldus S, von Kodolitsch Y, Rudolph V, Meinertz T: Systemic endothelial dysfunction as an early predictor of adverse outcome in heart failure. Arterioscler Thromb Vasc Biol 2005;25:1174-1179.

21 Gallieni M, Butti A, Guazzi M, Galassi A, Cozzolino M, Brancaccio D: Impaired brachial artery endothelial flowmediated dilation and orthostatic stress in hemodialysis patients. Int J Artif Organs 2008;31:34-42.

22 Georgianos PI, Sarafidis PA, Liakopoulos V: Arterial stiffness: a novel risk factor for kidney injury progression? Am J Hypertens 2015;28:958-965.

23 Lund LH, Aaronson KD, Mancini DM: Validation of peak exercise oxygen consumption and the Heart Failure Survival Score for serial risk stratification in advanced heart failure. Am J Cardiol 2005;95:734-741.

24 Sietsema KE, Amato A, Adler SG, Brass EP: Exercise capacity as a predictor of survival among ambulatory patients with end-stage renal disease. Kidney Int 2004;65:719-724. 
25 Capitanini A, Cupisti A, Mochi N, Rossini D, Lupi A, Michelotti G, Rossi A: Effects of exercise training on exercise aerobic capacity and quality of life in hemodialysis patients. J Nephrol 2008;21:738-743.

26 Painter P, Messer-Rehak D, Hanson P, Zimmerman SW, Glass NR: Exercise capacity in hemodialysis, CAPD, and renal transplant patients. Nephron 1986;42:47-51.

27 Lainscak M, Anker SD: Prognostic factors in chronic heart failure. A review of serum biomarkers, metabolic changes, symptoms, and scoring systems. Herz 2009;34:141-147.

28 Boutcher YN, Boutcher SH: Limb vasodilatory capacity and venous capacitance of trained runners and untrained males. Eur J Appl Physiol 2005;95:83-87.

29 Meredith IT, Currie KE, Anderson TJ, Roddy MA, Ganz P, Creager MA: Postischemic vasodilation in human forearm is dependent on endothelium-derived nitric oxide. Am J Physiol 1996;270(pt 2):H1435-H1440.

30 Carlsson I, Sollevi A, Wennmalm A: The role of myogenic relaxation, adenosine and prostaglandins in human forearm reactive hyperaemia. J Physiol 1987;389:147-161.

31 London GM, Pannier B, Agharazii M, Guerin AP, Verbeke FH, Marchais SJ: Forearm reactive hyperemia and mortality in end-stage renal disease. Kidney Int 2004;65:700-704.

32 Ghiadoni L, Cupisti A, Huang Y, Mattei P, Cardinal H, Favilla S, Rindi P, Barsotti G, Taddei S, Salvetti A: Endothelial dysfunction and oxidative stress in chronic renal failure. J Nephrol 2004;17:512-519.

33 Passauer J, Büssemaker E, Lassig G, Gross P: Kidney transplantation improves endothelium-dependent vasodilation in patients with endstage renal disease. Transplantation 2003;75:1907-1910. 